\title{
A Divulgação Científica do Tema "Água": uma Análise de Livros Didáticos de Ciências da Natureza
}

\author{
Bruna Sarpa Miceli \\ Sheila Cristina Ribeiro Rego \\ Marcelo Borges Rocha
}

\begin{abstract}
RESUMO
A divulgação científica (DC) consiste em um recurso responsável por veicular os conhecimentos da ciência para um público em geral. Quando inserida em livros didáticos, é capaz de auxiliar os alunos a partir do incentivo à leitura e à interpretação. Com base na importância do tema 'água' e nas suas contribuições para o conhecimento a respeito da necessidade de preservação deste recurso, questionou-se que diferenças podem ser encontradas nos textos inseridos nos livros em relação às suas fontes originais (textos de DC). O objetivo geral desta pesquisa consistiu em analisar a forma como foi realizada a reelaboração discursiva entre estes textos, investigando aspectos da linguagem e do grau de hibridez dos textos didáticos. Onze textos foram selecionados e retirados de três livros didáticos de Ciências do $6^{\circ}$ ano do Ensino Fundamental. Concluiu-se que a maioria dos textos foram classificados como editados por manterem características da sua fonte original. Tais textos também apresentaram termos explicativos e informativos, além de metáforas e analogias, que podem auxiliar na compreensão de conceitos científicos.
\end{abstract}

Palavras-chave: Divulgação científica. Água. Livros Didáticos. Textos Híbridos.

\section{The Scientific Divulgation of the Theme 'Water': An Analysis of the Science Textbooks}

\begin{abstract}
The Scientific divulgation (SD) consists of a resource responsible for transmitting the knowledge of science to a general public. When inserted into textbooks, is able to help the students from the incentive to reading and interpretation. Based on the importance of the theme 'water' and their contributions to the knowledge about the need for preservation of this resource, it was wondered what differences can be found in the texts entered in the books in relation to their original sources (SD's texts). The general objective of this research was to analyze the discursive re-elaboration between these texts, investigating aspects of the language and the degree of hybridity of the

Bruna Sarpa Miceli é mestranda no Programa de Pós-Graduação em Ciência, Tecnologia e Educação no Centro Federal de Educação Tecnológica Celso Suckow da Fonseca (CEFET/RJ), Avenida Maracanã, 229, 20271-110 Rio de Janeiro. Email brunasm213@gmail.com

Sheila Cristina Ribeiro Rego é Doutora pelo Núcleo de Tecnologia Educacional para a Saúde (NUTES/UFRJ). É professora no Centro Federal de Educação Tecnológica Celso Suckow da Fonseca (CEFET/RJ), Avenida Maracanã, 229, 20271-110 Rio de Janeiro. Email scrrego@gmail.com

Marcelo Borges Rocha é Doutor em Ciências Biológicas (Zoologia) pela Universidade Federal do Rio de Janeiro. É professor no Centro Federal de Educação Tecnológica Celso Suckow da Fonseca (CEFET/RJ), Avenida Maracanã, 229, 20271-110 Rio de Janeiro. Email rochamarcelo36@yahoo.com.br

Recebido para publicação em 26 jun. 2018. Aceito, após revisão, em 24 ago. 2018.

DOI: https://doi.org/10.17648/acta.scientiae.v20iss4id4228
\end{abstract}


textbooks. Eleven texts were selected and taken from three science textbooks of the sixth grade of elementary school. It was concluded that the most of the texts were classified as edited because they preserve characteristics of their original reference. This texts also presented explanatory and informative terms, as well as metaphors and analogies, which can help to understand scientific concepts.

Keywords: Scientific Divulgation. Water. Textbooks. Hybrid Texts.

\section{INTRODUÇÃO}

A divulgação científica (DC) constitui-se como recurso para a veiculação do conhecimento científico para o público em geral. No Brasil, a DC se consolidou a partir da chegada da Corte Portuguesa e da criação da Imprensa Régia, em 1810. A partir disto, diversas informações referentes ao conhecimento científico passaram a ser veiculadas em jornais como A Gazeta do Rio de Janeiro e O Patriota. Hoje, sabe-se que a DC está presente em meios de comunicação como as revistas, livros, rádios, televisão e na internet, além dos espaços não formais de ensino, como os museus (Moreira \& Massarani, 2002; Bueno, 2010; Souza \& Rocha, 2015a).

De acordo com Bueno (2010), a principal função da DC está relacionada com sua capacidade de permitir que o conhecimento científico atinja as diversas camadas populares. Segundo este autor, ela ainda é responsável por oferecer debates e reflexões a respeito de temas científicos atuais e que estejam relacionados ao cotidiano dos indivíduos. Corroborando com este pensamento, Zamboni (1997) afirma que a DC apresenta a função informativa e a educativa, já que a mesma visa partilhar, socialmente, o conhecimento científico e levar a informação para todos os tipos de público.

Neste sentido, Ferrari, Angotti e Cruz (2005) apresentam três objetivos da DC: o oferecer ao público um vocabulário científico de forma acessível que permita o entendimento da informação; divulgar os métodos de produção científica, ou seja, exemplificar cada etapa do processo de construção do conhecimento científico; e tornar mais clara e compreensível a relação entre os aspectos científicos, tecnológicos e sociais.

Zamboni (1997, p.114) define a DC como uma "atividade de reformulação", que pode ser entendida como uma série de adaptações sofridas desde o momento de sua produção (por pesquisadores) até que a mesma atinja um público o qual não possui um conhecimento científico e técnico da ciência. Tais alterações de discurso, denominadas por alguns autores como reelaboração discursiva, facilitam a compreensão e aproximação do público com o saber que está sendo transmitido (Martins, Cassab, \& Rocha, 2001; Souza \& Rocha, 2014; 2015b; Passeri, Aires, \& Rocha, 2017).

Martins, Cassab e Rocha (2001) afirmam que o discurso científico abrange diversas formações discursivas relacionadas a diferentes perfis de textos, como aqueles presentes nos artigos científicos, nos jornais, nas revistas e no livro didático. Para entendê-los, é necessário compreender as singularidades de cada texto, como o seu funcionamento, a maneira como são elaborados, o impacto que causam no leitor e especialmente em relação à forma como são realizadas as reelaborações discursivas de um texto para o outro. 
Dentro dessa discussão, Grillo, Dobranszky e Laplane (2004) analisaram e diferenciaram os discursos presentes no livro didático (discurso didático) e de revistas de DC. Segundo os autores, o discurso didático é veiculado para um público específico (o público escolar) e é mediado pelo professor, já o discurso encontrado nas revistas, conhecido como discurso jornalístico é transmitido através das mídias e é caracterizado por ser destinado a um público indeterminado.

Pensando na relação que existe entre a DC e o ensino, encontramos respaldo nos Parâmetros Curriculares Nacionais - PCNs (Brasil, 1997, p.81), que defendem a incorporação de textos e noticiários de divulgação no ambiente escolar:

Além do livro didático, outras fontes oferecem textos informativos: enciclopédias, livros paradidáticos, artigos de jornais e revistas, folhetos de campanhas de saúde, de museus, textos da mídia informatizada, etc. É importante que o aluno possa ter acesso a uma diversidade de textos informativos, pois cada um deles tem estrutura e finalidade próprias.

De acordo com esta recomendação, alguns autores afirmam que os textos de DC oferecem uma série de benefícios e auxiliam no esclarecimento de determinados conceitos, no desenvolvimento da interpretação e da leitura, além de contribuir para a inserção do aluno na sociedade através do contato com diversas informações e de torná-los indivíduos mais colaborativos e participantes da cultura científica (Martins, Cassab, \& Rocha, 2001; Puiati, Borowsky, \& Terrazzan, 2007; Ferreira \& Queiroz, 2011).

\section{Divulgação Científica e os Livros Didáticos}

O livro didático (LD) é considerado um recurso importante capaz de direcionar o processo de ensino-aprendizagem. Atualmente, ele ainda é prestigiado pela comunidade escolar, sendo utilizado tanto pelos alunos quanto pelos professores (Xavier, Freire, \& Moraes, 2006; Fioreze \& Delizoicov, 2015).

Dada a sua importância, diversos programas foram elaborados visando promover uma educação de qualidade, pautada na utilização dos LDs. Entre eles, pode-se citar a instituição do Programa Nacional do Livro Didático (PNLD) em 1985. O PNLD é utilizado até os dias atuais e visa a distribuição, de forma gratuita, de LDs para as escolas públicas do Brasil.

Com base na importância dos livros didáticos (Xavier, Freire \& Moraes, 2006; Fioreze \& Delizoicov, 2015; Dias et al., 2016), diversos trabalhos realizaram uma articulação entre a DC e os LDs com estudos baseados nas reelaborações discursivas (Martins, Cassab \& Rocha, 2001; Nascimento, 2005; Souza \& Rocha, 2014; 2017; Passeri, Aires \& Rocha, 2017). Estas reelaborações de discurso foram analisadas de acordo com os parâmetros definidos por Gomes (1995): acréscimo, eliminação, substituição e reordenação de informações. Vale a pena ressaltar que estes parâmetros também foram 
utilizados nesta pesquisa, atrelados a análise dos recursos linguísticos e do grau de hibridez apresentados pelos textos em relação à temática 'água'.

Neste sentido, é válido esclarecer que estamos chamando de textos de DC os retirados de jornais, revistas, artigos e blogs, enquanto o didático refere-se ao que sofreu alguma adaptação/reformulação do texto de DC ao ser inserido no LD. Portanto, diz-se que este último pode ser representado como um texto híbrido (Souza, 2017), por ser constituído por mais de um discurso, podendo alterar o significado e trazer diversas distorções.

\section{Divulgação Científica e a Temática 'Água'}

Os conhecimentos a respeito da temática 'água' são considerados pertinentes e relevantes a serem divulgados para o público em geral. Este fato deve-se à importância desempenhada por este recurso na manutenção da vida, na compreensão da vida na Terra, assim como na sua relação com o ser humano. Outra importância deste tema está pautada na necessidade de contribuir para que o aluno tenha conhecimento a respeito dos cuidados e da preservação necessária na gestão deste elemento vital. Além disso, é preciso compreender as possíveis consequências de determinadas ações humanas (Brasil, 1998; Otalara \& Carvalho, 2011).

Corroborando para a informação supracitada, os PCNs afirmam que:

O fato de que recursos como água doce, ar, solo, minerais e árvores podem ser reduzidos drasticamente pelo seu uso exagerado, inadvertido ou deliberado e que a atmosfera e o oceano têm capacidade limitada de absorver resíduos e reciclá-los naturalmente deve ser o pano de fundo das discussões. As alternativas naturais e tecnológicas para a restauração do ambiente e seus custos são importantes de serem veiculadas, ao lado das atitudes de preservação (Brasil, 1998, p.66).

Diante desta ideia referente à degradação ambiental como consequência para a escassez e poluição da água e que pode ser claramente observado na atualidade, chama-se a atenção para a importância de trabalhar questões sobre a água nas escolas, seja nas salas de aulas de Ciências (principalmente no $6^{\circ}$ ano do Ensino Fundamental II, onde o tema ganha 'destaque') ou a partir de projetos interdisciplinares com as demais disciplinas.

Alguns trabalhos destacam a relevância da questão hídrica e possuem como enfoque de pesquisa os LDs (Otalara \& Carvalho, 2011; Santana, Souza, \& Shuvartz, 2012; Borges, Araújo \& Bönmann, 2016; Freitas \& Marin, 2016; Passeri, Aires, \& Rocha, 2017).

Conforme o que foi apresentado, e tendo como base a temática referente à água, foi questionado que diferenças podem ser encontradas nos textos inseridos nos livros em relação às suas fontes originais (textos de DC). Acredita-se que tais textos de DC tenham sido adaptados para o LD a partir da utilização de uma linguagem mais acessível ao leitor, com a presença de termos explicativos, metáforas e analogias. 
Sendo assim, o objetivo geral desta pesquisa foi analisar o processo de reelaboração discursiva dos textos de DC ao serem inseridos no LD. Além disso, buscamos também, investigar aspectos da linguagem inseridos em ambos os textos (erros conceituais, metáforas e analogias) e o grau de hibridez dos textos didáticos.

\section{METODOLOGIA}

Este trabalho consiste em uma pesquisa qualitativa e bibliográfica, que segundo Gil (2002, p.44) desenvolve-se a partir de um "material já elaborado, constituído principalmente por livros e artigos científicos".

Para esta pesquisa, selecionou-se os livros Investigar e conhecer - Ciências da natureza, de Sônia Lopes; Ciências naturais - Aprendendo com o cotidiano, de Eduardo Leito do Canto e Projeto Apoema, de Ana Maria Pereira, Margarida Santana e Mônica Waldhelm. A escolha destes livros é justificada pela sua aprovação no PNLD de 2017 e pelo fato dos mesmos estarem presentes na listagem de livros mais distribuídos por componente curricular, neste caso, na disciplina de ciências. A série escolhida para análise foi o $6^{\circ}$ ano, onde a temática sobre os recursos hídricos é abordada.

Quadro 1. Coleções selecionadas para análise.

\begin{tabular}{|c|c|c|c|c|}
\hline CÓDIGO & LIVRO DIDÁTICO & AUTORES & EDITORA & EDIÇÃO \\
\hline L1 & $\begin{array}{c}\text { Investigar e conhecer: } \\
\text { ciências da natureza, 6 }{ }^{\circ} \text { ano }\end{array}$ & Sônia Lopes & Saraiva & $1^{\text {a }}$ ed, 2015 \\
\hline L2 & $\begin{array}{c}\text { Ciências naturais: aprendendo } \\
\text { com o cotidiano, } 6^{\circ} \text { ano }\end{array}$ & Eduardo Leite do Canto & Moderna & $5^{\text {a }}$ ed, 2015 \\
\hline L3 & $\begin{array}{c}\text { Projeto Apoema, Ciências } \\
6^{\circ} \text { ano }\end{array}$ & $\begin{array}{c}\text { Ana Maria Pereira; Margarida } \\
\text { Santana e Mônica Waldhelm }\end{array}$ & $\begin{array}{c}\text { Editora do } \\
\text { Brasil }\end{array}$ & $2^{\text {a } \text { ed, } 2015 .}$ \\
\hline
\end{tabular}

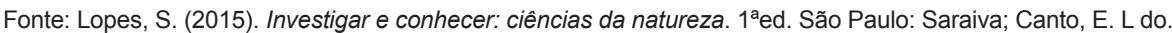
(2015). Ciências naturais: aprendendo com o cotidiano. $5^{\text {a }}$ ed. São Paulo: Moderna; Pereira, A. M, Santana, M \& Waldhelm, M. (2015). Projeto Apoema. $2^{\text {a }}$ Ed. São Paulo: Editora do Brasil.

\section{A Seleção dos Textos}

Durante a busca pelos textos referentes ao tema 'água', optou-se por restringir a análise aos textos cujas referências oferecidas eram pertencentes ao discurso jornalístico (como jornais e revistas - impressos ou digitais- e páginas da internet como blogs e noticiários). Isto se deve ao fato das mesmas serem consideradas fontes de acesso instantâneo ao público e por apresentarem uma linguagem coloquial e de fácil entendimento ao leitor, quando comparadas a outros discursos da DC (Targino, 2007). Neste sentido, os textos retirados de fontes como livros e artigos foram desconsiderados. Também foram retirados os textos cujas referências não eram fornecidas e que não estavam disponíveis ou não foram encontradas no endereço eletrônico oferecidos pelo autor do LD. 
Deste modo, foram encontrados nos três livros didáticos 11 textos para análise, codificados de $\mathrm{T} 1$ à T11. Chama-se atenção para o texto $\mathrm{T} 4 \mathrm{e} \mathrm{T} 6$, que foram retirados do mesmo endereço eletrônico.

Quadro 2. Total de textos encontrados na coleção Biologia.

\begin{tabular}{|c|c|c|c|c|}
\hline LIVRO & CÓDIGO & TíTULO & SEÇÃO RETIRADA & FONTE ORIGINAL \\
\hline L1 & $\mathrm{T} 1$ & $\begin{array}{l}\text { Aquífero Amazônia: um oceano } \\
\text { subterrâneo e desconhecido }\end{array}$ & Foi notícia & Jornal da Ciência \\
\hline L1 & T2 & Sem título & $\begin{array}{l}\text { Construir e aplicar } \\
\text { (exercícios) }\end{array}$ & Site da USP \\
\hline L1 & T3 & $\begin{array}{c}\text { É possível viver com } 110 \text { litros } \\
\text { de água por dia? Veja como } \\
\text { seria sua vida }\end{array}$ & Foi notícia & Site 'UOL notícias' \\
\hline L1 & T4 & Sem título & $\begin{array}{l}\text { Construir e aplicar } \\
\text { (exercícios) }\end{array}$ & $\begin{array}{l}\text { Site governamental } \\
\text { (Planalto) }\end{array}$ \\
\hline L2 & T5 & O Brasil pede água & Em destaque & Site ‘Época’ \\
\hline L2 & T6 & O que é pegada hídrica? & Em destaque & Site 'WWF Brasil' \\
\hline L2 & $\mathrm{T7}$ & Falta de saneamento básico & Em destaque & Site 'Época' \\
\hline L3 & T8 & Aquífero Guarani & Indo além & Site 'UOL' \\
\hline L3 & T9 & Os direitos da água & Trabalho em equipe & $\begin{array}{c}\text { Site da USP- Direitos } \\
\text { humanos }\end{array}$ \\
\hline L3 & T10 & Entenda sua conta de água & Ciências e cidadania & Sites da SABESP \\
\hline L3 & T11 & Reúso da água no Brasil & $\begin{array}{c}\text { Ciência, Tecnologia e } \\
\text { Sociedade }\end{array}$ & Revista 'Exame', Abril. \\
\hline
\end{tabular}

\section{Análise dos Textos}

Para a análise dos 11 textos encontrados, utilizou-se a análise de conteúdo (AC), proposta por Bardin (1977). A AC é compreendida como "um conjunto de técnicas de análise das comunicações visando obter, por procedimentos sistemáticos e objetivos de descrição do conteúdo das mensagens, indicadores (quantitativos ou não) que permitam a inferência de conhecimentos" (Bardin, 1977, p.42). Vale a pena ressaltar que, para esta metodologia, utilizou-se a análise categorial, que corresponde a uma das técnicas mais antigas e utilizadas da $\mathrm{AC}$ e se baseia no desmembramento de um texto segundo categorias ou unidades (Bardin, 1977). Deste modo, três categorias foram elencadas para esta pesquisa:

A-Reelaboração discursiva: Nesta categoria, ambos os textos (texto de DC e texto didático) foram comparados de acordo com os padrões fornecidos por Gomes (1995): acréscimos, exclusões, substituições e reordenações de informações. 
B-Linguagem: Analisou-se a presença de possíveis erros conceituais nos textos, metáforas e analogias.

C- Hibridez dos textos didáticos: Este item foi pautado de acordo com a tese de Souza (2017), que, a partir da comparação entre os textos, classifica o texto didático em: (i) textos híbridos: textos os quais sofreram grandes re-elaborações discursivas, parecendose pouco com as fontes originais; (ii) textos semi-híbridos: textos que sofreram grandes exclusões de informações e poucos acréscimos, reordenações e substituições de dados; e (iii) textos editados: textos que não possuem modificações significativas em relação ao conteúdo, mas realizam exclusão de dados ou palavras.

\section{RESULTADOS E DISCUSSÃO}

\section{Reelaboração Discursiva}

Nesta categoria, consideraram-se as alterações realizadas do texto original para o texto presente no livro didático segundo os seguintes aspectos: eliminação, acréscimo, reordenação e substituição de informação.

Em relação às eliminações, estas se fizeram presentes em todos os textos analisados. Os acréscimos, por sua vez, puderam ser observados em T1, T9 e T11, já as substituições foram notadas apenas em T9 e T11. Ressalta-se que o único elemento da reelaboração discursiva que não foi observado em nenhum dos textos foram as reordenações de informações.

O primeiro texto analisado (T1) aborda o aquífero localizado na Amazônia e apresenta um pequeno acréscimo (referente à data em que ocorreu a Reunião Anual da Sociedade Brasileira para o Progresso da Ciência), que pode ser observada no seguinte fragmento “... nesta sexta feira 25 [2014], durante a $66^{a}$ Reunião Anual...”. A partir deste acréscimo, infere-se que o autor preocupou-se em trazer informações recentes ao revelar a data em que esta reunião foi realizada, uma vez que o LD apresenta sua edição no ano de 2015 .

Em outro momento de T1, o autor manteve dados e opiniões apresentados por especialistas (como o geólogo da Universidade Federal do Pará, Francisco de Assis de Abreu) a respeito do aquífero. Este fato garante maior veracidade e confiabilidade da informação (Quadro 3). Além disso, ao preservar a fala de pesquisadores nestes tipos de textos, o autor também colaborou para uma visão de ciência atrelada a diversos estudos e pesquisas, diferentemente do que foi observado por Passeri, Aires e Rocha (2017) e Souza e Rocha (2014), onde notou-se alterações da visão de natureza da ciência de um texto para o outro após a retirada de falas de pesquisadores. Tal mudança contribuiu em ambas as pesquisas, para uma visão ingênua de ciência, de forma que as técnicas utilizadas e os procedimentos dos estudos não são contemplados pelo leitor. 
Quadro 3. Acréscimo (negrito) realizado em T1.

\begin{tabular}{|c|c|}
\hline TEXTO ORIGINAL & TEXTO DIDÁTICO \\
\hline 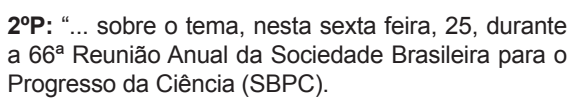 & $\begin{array}{l}2^{\circ} \text { P: “... sobre o tema, nesta sexta feira, } 25 \text { [2014], } \\
\text { durante a } 66^{\text {a }} \text { Reunião Anual da Sociedade Brasileira } \\
\text { para o Progresso da Ciência (SBPC). }\end{array}$ \\
\hline $\begin{array}{l}5^{\circ} \text { P: "O geólogo da UFPA disse que não há } \\
\text { necessidade do uso dessa água a médio prazo e } \\
\text { revelou que sua real importância está na manutenção } \\
\text { do sensível equilíbrio entre a floresta e os recursos } \\
\text { hídricos. "Esse equilíbrio é responsável por importantes } \\
\text { parâmetros climáticos, sobretudo o regime de } \\
\text { chuvas. O SAGA é sem dúvida uma reserva aquífera } \\
\text { estratégica para o Brasil, na medida em que representa } \\
80 \% \text { da água que faz funcionar o ciclo hidrológico na } \\
\text { Amazônia", disse Abreu. }\end{array}$ & $\begin{array}{l}5^{\circ} \text { P: "O geólogo da UFPA disse que não há } \\
\text { necessidade do uso dessa água a médio prazo } \\
\text { e revelou que sua real importância está na } \\
\text { manutenção do sensível equilíbrio entre a floresta e } \\
\text { os recursos hídricos. "Esse equilíbrio é responsável } \\
\text { por importantes parâmetros climáticos, sobretudo } \\
\text { o regime de chuvas. O SAGA é sem dúvida uma } \\
\text { reserva aquífera estratégica para o Brasil, na medida } \\
\text { em que representa } 80 \% \text { da água que faz funcionar o } \\
\text { ciclo hidrológico na Amazônia", disse Abreu. }\end{array}$ \\
\hline
\end{tabular}

Fonte: Os autores, 2018.

O segundo texto (T2) realiza apenas exclusões de quatro parágrafos do texto original que não são sinalizadas no texto didático. Estas eliminações foram feitas de forma que o autor do LD apropriou-se apenas do último parágrafo, o qual retrata a questão da água como uma fonte para a origem da vida (Quadro 4). Tais retiradas de informações comprometeram o caráter do texto, uma vez que este autor retira o contexto histórico dos dados apresentados no site da Universidade de São Paulo (a qual possui grande relevância e conceito). Souza e Rocha (2014) observaram durante a reelaboração de um texto de ecologia que o texto didático, ao reduzir o conteúdo, eliminou também aspectos importantes a serem abordados no LD.

Quadro 4. Eliminação realizada no texto didático de $T 2$.

\begin{tabular}{|c|c|}
\hline TEXTO ORIGINAL & TEXTO DIDÁTICO \\
\hline $\begin{array}{l}\text { 3P: "Quando se originou a vida? } \\
\text { Evidências sugerem que a vida surgiu pela primeira vez por volta 3,5 } \\
\text { bilhões de anos atrás. As evidências são formadas por microfósseis } \\
\text { (fósseis que são muito pequenos para serem vistos sem a ajuda } \\
\text { do microscópio) e estruturas rochosas antigas encontradas no Sul } \\
\text { da África e Austrália chamadas estromatólitos..." } \\
4^{\circ} \mathrm{P}: \text { "Estromatólitos ainda são produzidos por micróbios } \\
\text { hoje. Esses estromatólitos modernos são incrivelmente } \\
\text { similares aos antigos estromatólitos que fornecem evidências..." } \\
5^{\circ} \mathrm{P}: \text { Onde a vida se originou? } \\
\text { Cientistas estão explorando vários possíveis locais para a origem } \\
\text { da vida, incluindo poças de maré e fontes térmicas..." }\end{array}$ & $\begin{array}{l}1^{\circ} \mathrm{P}: \text { "Cientistas estão explorando } \\
\text { vários possíveis locais para a origem da } \\
\text { vida, incluindo poças de maré e fontes } \\
\text { térmicas ...." }\end{array}$ \\
\hline
\end{tabular}

Notou-se que em T3 foram realizadas duas eliminações. Uma era sinalizada com o uso de reticências e a outra, não. A primeira exclusão é referente a um dado da ONU 
(Organização das Nações Unidas) sobre a quantidade de água a ser utilizada por dia. A retirada desta informação provavelmente foi realizada por ela responder a pergunta presente no título "É possível viver com 110 litros de água por dia? Veja como seria sua vida" e por inconscientemente influenciar na opinião dos jovens e não estimulá-los a refletir sobre tal possibilidade. A segunda exclusão é referente ao nome do próprio noticiário que veicula a reportagem: "Com a ajuda de uma ferramenta disponível no site da Sabesp (Companhia de Saneamento Básico do Estado de São Paulo), a reportagem do UOL fez os cálculos... ". Acredita-se que o texto didático tenha retirado essas informações a fim de não apresentar a sua verdadeira fonte de consulta (site do UOL) o que permite inferir que o autor não valoriza a sua referência de busca (Quadro 5).

Quadro 5. Eliminações (em itálico) realizadas em T3.

\begin{tabular}{|c|c|}
\hline TEXTO ORIGINAL & TEXTO DIDÁTICO \\
\hline $\begin{array}{l}1^{\circ} \mathrm{P} \text { : “Segundo a ONU (Organização das Nações Unidas), } \\
110 \text { litros de água por dia é suficiente para atender as } \\
\text { necessidades básicas de uma pessoa. }\end{array}$ & $1^{\circ} \mathrm{P}:$ :Em 2013, o consumo..." \\
\hline $2^{\circ}$ P: "Em 2013, o consumo..." & $3^{\circ} \mathrm{P}$ : "Com a ajuda de uma ferramenta disponível \\
\hline $\begin{array}{l}4^{\circ} \text { P: "Com a ajuda de uma ferramenta disponível no site } \\
\text { da Sabesp (Companhia de Saneamento Básico do Estado } \\
\text { de São Paulo), a reportagem do UOL fez os cálculos e } \\
\text { concluiu..." }\end{array}$ & $\begin{array}{l}\text { Básico do Estado de São Paulo), a reportagem } \\
\text { [...] fez os cálculos e concluiu..." }\end{array}$ \\
\hline
\end{tabular}

Assim como T2 e T3, T4 apresentou somente eliminações de informações. O dado retirado era referente à data de publicação do noticiário: “... divulgada nesta quinta-feira (18). ”. Outras exclusões não sinalizadas correspondiam ao restante do texto e não tratavam da temática 'água'. As mesmas abordavam outras pesquisas referentes às taxas de analfabetismo, bens duráveis, inclusão digital e etc. Diante destas exclusões, pode-se dizer que as mesmas não eram relevantes para a compreensão dos recursos hídricos.

Em T5 foram observadas seis exclusões sinalizadas. Estas eliminações englobaram tanto frases quanto parágrafos inteiros. Acredita-se que no texto didático, o autor tenha retirado a frase "Ambos os futuros, neste momento, são igualmente possíveis", pois anteriormente a isso, ele realizou uma exclusão de um parágrafo inteiro referente a um dos 'futuros' relacionados à questão hídrica e, portanto, tal frase tenha perdido sua relevância no LD. Ainda no final deste mesmo terceiro parágrafo, o autor retira outra frase: “A resposta está no mau uso do recurso. ”, que consistia em uma resposta de uma pergunta apresentada sobre as razões da escassez de água no Brasil. Neste caso, possivelmente o autor retirou tal afirmação a fim de incentivar que cada leitor pudesse refletir sobre os motivos que levaram a falta deste recurso (Quadro 6). 
Quadro 6. Exclusões de frases realizadas no terceiro parágrafo do texto didático 5.

\begin{tabular}{|c|c|}
\hline TEXTO ORIGINAL & TEXTO DIDÁTICO \\
\hline $\begin{array}{l}4^{\circ} \mathrm{P} \text { : “Ambos os futuros, neste momento, são igualmente } \\
\text { possíveis. O Brasil é uma potência da água. Não precisa } \\
\text { sustentar nem } 3 \% \text { da população mundial, mas abriga } 12 \% \\
\text { da água doce disponível no globo. Essa parcela aumenta } \\
\text { para } 18 \% \text {, se contarmos a água que flui dos países } \\
\text { vizinhos para o território nacional. Como um país desses } \\
\text { pode comemorar o Dia da Água ( } 22 \text { de março) mergulhado } \\
\text { numa crise energética e à beira do racionamento nas } \\
\text { torneiras? A resposta está no mau uso do recurso." }\end{array}$ & $\begin{array}{l}3^{\circ} \mathbf{P}: \text { "[...] O Brasil é uma potência da água. Não } \\
\text { precisa sustentar nem } 3 \% \text { da população mundial, } \\
\text { mas abriga } 12 \% \text { da água doce disponível no } \\
\text { globo. Essa parcela aumenta para } 18 \% \text {, se } \\
\text { contarmos a água que flui dos países vizinhos } \\
\text { para o território nacional. Como um país desses } \\
\text { pode comemorar o Dia da Água ( } 22 \text { de março) } \\
\text { mergulhado numa crise energética e à beira do } \\
\text { racionamento nas torneiras? [...]." }\end{array}$ \\
\hline
\end{tabular}

O sexto texto (T6) utiliza-se apenas de um pequeno parágrafo da sua fonte original, ou seja, o restante do texto é eliminado. Porém, T6 sinaliza apenas uma exclusão através da utilização das reticências. Tal eliminação refere-se a uma explicação do significado de pegada hídrica: "é uma ferramenta de gestão de recursos hídricos que” (Quadro 7). Além deste único parágrafo, o texto didático também mantém uma tabela retirada da referência de origem.

Quadro 7. Exclusão de informação observada em T6.

\begin{tabular}{|l|l|}
\hline TEXTO ORIGINAL & TEXTO DIDÁTICO \\
\hline $\begin{array}{l}4^{\circ} \text { P: “A Pegada Hídrica é uma ferramenta de gestão de } \\
\text { recursos hídricos que indica o consumo de água doce com } \\
\text { base em seus usos direto e indireto..." }\end{array}$ & $\begin{array}{l}\text { 1P: “A Pegada Hídrica [...] indica o consumo } \\
\text { de água doce com base em seus usos direto } \\
\text { e indireto...” }\end{array}$ \\
\hline
\end{tabular}

O sétimo texto (T7), possui como fonte original a mesma referência utilizada em T5. Porém, o texto didático T7 utiliza-se de dois parágrafos que foram eliminados no texto anterior (T5). Portanto, em relação a T7 e sua referência original, o texto utilizase apenas de dois parágrafos que abordavam a questão do saneamento básico e exclui todo o restante. Tais eliminações não são sinalizadas e acredita-se que o autor tenha selecionado tal informação e tenha optado em abordá-la em outro capítulo do LD referente à contaminação da água. Vale a pena lembrar que a informação presente em T7 apresenta um acréscimo, porém não sofreu grandes alterações para a sua fonte original e deste modo, dados referentes à pesquisa realizada pela Agência Nacional das Águas é mantida, conforme pode ser observado no quadro 8. Neste sentido, é possível observar que o texto didático se preocupa em relatar os resultados da pesquisa, problematizando tal falta de saneamento básico presentes nas cidades. Nota-se ainda, neste fragmento, que ambos os textos contribuem para uma visão ciência 'não mistificada', uma vez que evidencia que é preciso realizar testes e experimentos para avaliar determinado elemento (neste caso, a água). 
Quadro 8. Acréscimo realizado em $T 7$ em relação à sua fonte original.

\begin{tabular}{|c|c|}
\hline TEXTO ORIGINAL & TEXTO DIDÁTICO \\
\hline $\begin{array}{l}10^{\circ} \text { P: "Uma pesquisa da Agência Nacional de Águas } \\
\text { (ANA) feita no ano passado encontrou água "ruim" ou } \\
\text { "péssima" em } 44 \% \text { dos pontos de coleta em cidades } \\
\text { no país. Tratá-la e torná-la adequada ao consumo fica } \\
\text { mais caro e demorado, quando não inviável." }\end{array}$ & $\begin{array}{l}\text { 10 P: "Uma pesquisa da Agência Nacional de Águas } \\
\text { (ANA) feita no ano passado [2013] encontrou água } \\
\text { "ruim" ou "péssima" em } 44 \% \text { dos pontos de coleta } \\
\text { em cidades no país. Tratá-la e torná-la adequada ao } \\
\text { consumo fica mais caro e demorado, quando não } \\
\text { inviável." }\end{array}$ \\
\hline
\end{tabular}

Em T8, três eliminações são realizadas através das reticências, duas de frases inteiras e uma de parágrafos inteiros. Mais uma vez, acredita-se que as eliminações tenham sido feitas buscando levar apenas o que o autor julgou ser necessário para abordagem no LD, já que os textos originais, em sua maioria, eram extensos (Quadro 9). Tais reduções significativas também foram observadas por Passeri, Aires e Rocha (2017) durante a reelaboração de um texto cuja temática era a água. Porém, durante a análise de reelaboração de um texto referente ao Cerrado, Martins, Cassab e Rocha (2001) observaram também que o texto didático reduziu drasticamente o conteúdo original, eliminando termos léxicos que possivelmente poderiam dificultar a compreensão do leitor.

Quadro 9. Exemplo de eliminação encontrada em T8.

\begin{tabular}{|l|l|}
\hline \multicolumn{1}{|c|}{ TEXTO ORIGINAL } & \multicolumn{1}{|c|}{ TEXTO DIDÁTICO } \\
\hline $\begin{array}{l}4^{\circ} \text { P: "Por esse cenário, crescem em importância os } \\
\text { aquíferos. Eles são grandes depósitos subterrâneos } \\
\text { de água alimentados pelas chuvas que se infiltram no } \\
\text { subsolo. Por sua vez, alimentam mananciais..." }\end{array}$ & $\begin{array}{l}4^{\circ} \mathrm{P}: \text { " [...] Eles são grandes depósitos subterrâneos } \\
\text { de água alimentados pelas chuvas que se infiltram no } \\
\text { subsolo. Por sua vez, alimentam mananciais..." }\end{array}$ \\
\hline
\end{tabular}

O nono texto (T9) realiza um acréscimo e uma substituição de informação, além de três eliminações sinalizadas pelo uso de reticências. Acredita-se que o acréscimo e a substituição tenham sido feitos com o objetivo de tornar o texto didático mais organizado e compreensível para que o assunto sobre os Direitos Humanos da água fossem introduzidos (Quadro 10). Em relação às exclusões, alguns artigos destes Direitos Humanos foram eliminados do texto, como o artigo $2^{\circ}, 5^{\circ}, 8^{\circ}, 9^{\circ}$ e $10^{\circ}$. Possivelmente o autor buscou trazer apenas os artigos que ressaltassem a importância deste recurso para os seres humanos e para o planeta, além da necessidade de conservá-lo. Estes recursos de acréscimo e substituição também foram notados por alguns autores em pequenos fragmentos do texto didático a fim de torná-los mais explicativos (Nascimento, 2005; Souza \& Rocha, 2014; Passeri, Aires, \& Rocha, 2017). 
Quadro 10. Acréscimo (negrito) e substituição (negrito e sublinhado) presentes em T9.

\begin{tabular}{|c|c|}
\hline TEXTO ORIGINAL & TEXTO DIDÁTICO \\
\hline $\begin{array}{l}1^{\circ} \mathrm{P} \text { : A presente Declaração Universal dos Direitos da } \\
\text { Água foi proclamada tendo como objetivo atingir todos os } \\
\text { indivíduos, todos os povos e todas as nações, para que } \\
\text { todos os homens, tendo esta Declaração constantemente } \\
\text { no espírito, se esforcem, através da educação e do ensino, } \\
\text { em desenvolver o respeito aos direitos e obrigações } \\
\text { anunciados e assomam, com medidas progressivas de } \\
\text { ordem nacional e internacional, o seu reconhecimento e a } \\
\text { sua aplicação efetiva. } \\
2^{\circ} \text { P: "Art. } 1^{\circ} \text { - A água faz parte do patrimônio do planeta } \\
\text {...." }\end{array}$ & $\begin{array}{l}1^{\circ} \mathrm{P}: \text { "Em } 22 \text { de marco de 1992, a ONU } \\
\text { instituiu o Dia Mundial da Água, que } \\
\underline{\text { vem sendo lembrado por entidades }} \\
\text { governamentais e não governamentais } \\
\text { como mais um dia mundial de luta em } \\
\text { defesa da preservacão da natureza. Confira } \\
\text { abaixo o trecho da Declaração Universal dos } \\
\text { Direitos da Água. } \\
2^{\circ} \text { P: "Art. } 1^{\circ} \text { A água faz parte do patrimônio } \\
\text { do planeta ...." }\end{array}$ \\
\hline
\end{tabular}

O penúltimo texto analisado (T10) não realiza grandes alterações de um texto para o outro e apenas uma eliminação sinalizada é feita. A mesma foi encontrada no primeiro parágrafo onde o autor retira o termo 'na SABESP' durante uma explicação sobre o que seria o número de RGI presente na conta da água. (Quadro 11). O restante do texto didático foi reproduzido com base no texto original, retirado do site da SABESP.

Quadro 11. Eliminação feita do texto original para o texto didático 9.

\begin{tabular}{|l|l|}
\hline \multicolumn{1}{|c|}{ TEXTO ORIGINAL } & \multicolumn{1}{|c|}{ TEXTO DIDÁTICO } \\
\hline $\begin{array}{l}1^{\circ} \mathrm{P}: \text { "1.RGI: é o número de identificação do seu imóvel } \\
\text { na Sabesp" }\end{array}$ & $\begin{array}{l}1^{\circ} \mathrm{P}: \text { "1.RGI: é o número de identificação do seu } \\
\text { imóvel [...]" }\end{array}$ \\
\hline
\end{tabular}

No texto 11 (T11), foi possível observar um acréscimo de informação, onde novamente o autor realiza uma introdução do que será abordado no texto retirado de sua fonte original. Além disso, notou-se sete exclusões de informações (uma delas não sinalizada), uma vez que o texto didático utiliza apenas quatro parágrafos do texto original e substituições de informações (Quadro 12). Observou-se também uma pequena substituição e correção de vocabulário no sexto parágrafo do texto didático, onde o termo 'na' foi substituído por 'à', o que demonstra a preocupação do autor do livro com a veiculação de possíveis conceitos errôneos. Vale lembrar que as substituições também foram observadas por Souza e Rocha (2014), onde uma palavra era substituída por uma similar ou sinônima a ela, como no caso do trecho presente na referência original 'disponibilidade de alimentos' para 'quantidade de presas' no LD. Nascimento (2005) também notou substituição de informação no verbo 'trabalhar', onde no texto original era apresentado 'trabalham' no presente e no texto didático este mesmo verbo estava no passado: 'trabalhavam'. Acredita-se, desta forma, que as substituições visam tornar os textos mais claros para o leitor por meio de pequenas alterações de palavras ou letras. 
Quadro 12. Acréscimo (negrito), exclusão (itálico) e substituição (negrito e sublinhado) observados em T11.

\begin{tabular}{|c|c|}
\hline TEXTO ORIGINAL & TEXTO DIDÁTICO \\
\hline $\begin{array}{l}14^{\circ} \text { P: “... Para Brandão, a disseminação do reúso } \\
\text { é uma questão de tempo. Na medida em que a } \\
\text { demanda de água aumentar e a cobrança pelo uso } \\
\text { se expandir, a alternativa da reciclagem acabará } \\
\text { fazendo parte do dia a dia das empresas." }\end{array}$ & $\begin{array}{l}1^{\circ} \mathrm{P}: \text { "O abastecimento público de água doce já é um } \\
\text { problema em algumas metrópoles brasileiras..." } \\
2^{\circ} \mathrm{P}: \text { "Muitas empresas começam a buscar soluções } \\
\text { que possam amenizar a situação...” } \\
6^{\circ} \mathrm{P}: \text { :[...] À medida que a demanda de água aumentar } \\
\text { e a cobrança pelo uso se expandir, a alternativa da } \\
\text { reciclagem acabará fazendo parte do dia a dia das } \\
\text { empresas." }\end{array}$ \\
\hline
\end{tabular}

\section{Linguagem}

Nesta categoria, analisou-se a presença de possíveis erros conceituais, além de metáforas e analogias. Vale lembrar que a analogia consiste em "comparação entre dois conceitos/fenômenos/assuntos que mantém certa relação de semelhança entre ambos" (Silva, Pimentel \& Terrazzan, 2011, p.164). Já as metáforas “são frequentemente usadas na construção do conhecimento e na comunicação em ciência. Elas também são muito usadas no conhecimento escolar, como tem sido reconhecido há muito tempo pela pesquisa em educação científica” (Goldbach \& El-Hani, 2008, p.165).

Em T1 não foram observados erros conceituais, porém encontrou-se três termos explicativos. No primeiro, é apresentada a definição do Sistema Aquífero Grande Amazônia: “... Sistema Aquífero Grande Amazônia-SAGA, que, segundo pesquisadores, é um conjunto de camadas geológicas com reservas expressivas de água subterrânea." . O segundo corresponde ao significado de transforonteiriço: "Esse sistema é transfronteiriço, pois atinge outros países..." e o terceiro consiste em uma explicação sobre o que seria o ciclo hidrológico da água: "O ciclo hidrológico é o caminho que a água percorre depois que evapora do oceano... ”. Os termos explicativos foram observados por Ferreira e Queiroz (2011) a partir de uma análise de textos de DC da revista Ciência Hoje. Tais explicações, segundo as autoras, são apresentadas nos textos com o objetivo de facilitar a compreensão de determinado conceito.

Ainda em T1, notou-se a presença de duas analogias. No fragmento "A qualidade de uso é algo que ainda estamos engatinhando", a palavra 'engatinhando' faz uma analogia no sentido de que seria algo que ainda está sendo estudado e processado pelos pesquisadores. Já o segundo fragmento “... até bater nos Andes”, o verbo 'bater' é utilizado com sentido semelhante aos verbos 'atingir' e 'alcançar'. Tal recurso linguístico também busca aproximar o leitor do conhecimento através de termos simples que são utilizados no cotidiano.

O T2, apesar de conter uma linguagem acessível ao leitor, não se utilizou de recursos linguísticos a fim de facilitar a compreensão do aluno. O termo "fonte hidrotérmica" poderia vir acompanhada de seu conceito a fim de contribuir para um caráter mais didático do texto, com explicações. Um fato semelhante foi observado em T3, que embora seja 
um texto de fácil compreensão e informativo, não utilizou-se de metáforas e analogias. A exceção deste último texto foi a apresentação do significado da sigla SABESP (Companhia de Saneamento Básico do Estado de São Paulo). Vale lembrar que os erros conceituais não foram observados em ambos os textos (T2 e T3).

Em T4, observou-se a presença das siglas referentes ao Instituto Brasileiro de Geografia e Estatística (IBGE) e da Pesquisa Nacional por Amostra de Domicílios (PNAD), ambas com seus respectivos significados. Notou-se também que este texto apresentava mais dados estatísticos e, portanto não utilizou-se de recursos linguísticos, assim como os erros conceituais, que também não foram encontrados nestes textos.

Observou-se uma metáfora em T5 na seguinte frase: "O Brasil é uma potência da água”. Neste sentido, entende-se que é atribuído ao país o potencial da água pelo fato do mesmo possuir tal recurso em abundância. Outra metáfora pode ser percebida no título "O Brasil pede água”, onde o texto chama atenção para a falta d'água enfrentada principalmente no Estado de São Paulo, apesar do país possuir chuvas em abundância. Erros conceituais e analogias não foram observados. As metáforas também foram encontradas nos textos didáticos analisados por Souza e Rocha (2017) visando facilitar o entendimento dos leitores.

O T6 apresentou apenas uma analogia presente no título do texto "O que é pegada hídrica?'”. Neste caso, o termo 'pegada' faz uma analogia à palavra 'rastro', 'gestão', no sentido de que a água é 'mensurada' de acordo com o seu consumo médio da população. Não foram observados erros conceituais nos textos de T6.

O texto T7 não apresentou erros conceituais, termos explicativos ou recursos linguísticos. Porém, o texto foi considerado informativo, uma vez que apresentava dados estatísticos “... encontrou água "ruim” ou "péssima” em $44 \%$ dos pontos de coleta em cidades no país...” e informações complementares como no seguinte fragmento: “... quatro em cada dez moradores das cidades brasileiras não contam com saneamento básico (fora das cidades, a situação é ainda pior - mais da metade dos brasileiros não tem saneamento)."

Em T8, foi possível observar a presença de termos explicativos, como a definição de aquíferos "Eles são grandes depósitos subterrâneos de água alimentados pelas chuvas que se infiltram no subsolo" e do aquífero Guarani "O aquífero Guarani é o principal manancial de água doce da América do Sul. ”. Notou-se também a presença de termos informativos como "Não custa recapitular: só cerca de 3\% de toda a água do planeta é doce”. Além disso, duas analogias também foram encontradas neste texto sobre a infiltração da água até atingir os aquíferos: "A água costuma preencher os espaços entre os sedimentos arenosos, como se fosse em uma tigela com areia e água misturados, ou se infiltra pelas fraturas, ou rachaduras, das rochas - pense em uma imensa esponja que absorve a água e você vai ter a idéia mais próxima do que é um aqüífero”. Vale lembrar que as analogias facilitam a compreensão de determinados conceitos a partir da apresentação de termos semelhantes a eles e comuns no cotidiano (Souza \& Rocha, 2015a). 
O T9, por ser retirado da Declaração Universal dos Direito Humanos, apresenta uma linguagem mais formal, mas ainda compreensível ao leitor. Deste modo, o texto não apresenta recursos linguísticos como metáforas e analogias ou termos explicativos. Vale lembrar que assim como os demais textos anteriores, T9 também não apresentou erros conceituais.

O décimo texto (T10) apresenta diversos termos explicativos, uma vez que o texto é intitulado 'Entenda sua conta de água' e explica cada item presente na mesma. Como exemplo, podemos citar os seguintes fragmentos: "4. Data de leitura: é a data em que a Sabesp fez a leitura em seu hidrômetro" e "6. Condição de leitura: mensagem que indica o que ocorreu no momento em que o profissional realizou a leitura do hidrômetro... ”. Vale lembrar que metáforas, analogias e erros conceituais não foram observados neste texto.

Por último, T11, assim como T9 não apresentou recursos linguísticos. O texto, por sua vez, possui um caráter informativo, que pode ser observado nos seguintes fragmentos: “[...] O Projeto de Reúso de Água, da Embrapa e da Universidade Federal de Campina Grande, na Paraíba, fornecerá 40000 litros de água reciclada por hora para a agricultura.[...]” " “...Um estudo da Sanepar estima que, apenas na região metropolitana de Curitiba, dos 7 bilhões de litros de esgoto gerados por mês, 4,8 bilhões possam ser revendidos como água de reúso. ". Em relação aos erros conceituais, vale lembrar que o texto didático realiza uma pequena correção de vocabulário do texto original para o texto didático. Tal correção pôde ser observada a partir da substituição do termo ' na' para o termo 'à', presente no quadro 12 .

\section{Hibridez dos Textos Didáticos}

Conforme observado a partir da reelaboração discursiva, os textos T2, T3 T4, T5, T6, T7, T8 e T10 sofreram apenas exclusões de informações. Desta forma, de acordo com a classificação de Souza (2017), estes mesmos textos foram considerados textos editados por serem muito semelhantes com as suas fontes originais. Os textos T1, T9 e T11, além das exclusões realizaram outras alterações para o LD, como acréscimo e/ou substituições e por este motivo, foram considerados textos semi-híbridos, já que alteraram um pouco o conteúdo em relação à fonte original. Os textos classificados como híbridos (que são significativamente alterados) não foram observados nas análises.

\section{CONSIDERAÇÕES FINAIS}

Destaca-se a importância desempenhada pela DC na construção e aproximação do conhecimento com a população, especialmente quando abordada em LDs na forma de textos de DC, já que os mesmos auxiliam no desenvolvimento de aptidões de jovens a partir do incentivo à leitura e à interpretação. Ressalta-se também a importância de trabalhar a questão dos recursos hídricos por meio destas ferramentas, uma vez que a 
temática da água necessita ser bem compreendida, a fim de que haja mais atenção para sua utilização e preservação.

Com base na análise feita em relação à reelaboração discursiva, notou-se que os elementos de eliminação estiveram presentes na maioria dos textos e que possivelmente tal recurso foi utilizado pelo fato do autor do LD querer reduzir as informações e levar apenas o que ele julgou ser necessário para o livro e que fosse pertinente ao conteúdo. Os acréscimos e substituições foram observados em menor quantidade, mas acredita-se que tais recursos foram realizados com a finalidade de tornar o texto didático mais claro e compreensível ao seu leitor. Em relação às reordenações, as mesmas foram os únicos recursos da reelaboração discursiva que não foram observados em nenhum dos textos analisados.

Apesar da maioria dos textos serem considerados textos editados por apresentarem poucas alterações em relação à fonte original, durante a análise da linguagem dos onze textos, notou-se que boa parte dos textos apresentaram algum tipo de recurso linguístico que auxiliava na compreensão do conteúdo e que foi mantido ao ser incorporado no LD. Desta forma, percebeu-se o uso de termos explicativos, informativos, metáforas e analogias que facilitavam a aproximação daquele conhecimento com o leitor através do uso de um vocabulário comum no cotidiano.

Diante da análise realizada, os onze textos analisados foram considerados relevantes e acessíveis para serem utilizados durante o ensino de ciências, uma vez que tratam a importância da questão hídrica (cujo caráter é interdisciplinar) e chamam atenção para diversos aspectos que devem ser abordados no ensino (como por exemplo, a utilização da água e a consequência do seu mau uso, além da necessidade de preservação deste elemento). Deste modo, estes textos analisados buscam levar mais informações e conhecimentos aos alunos, assim como visa a DC.

Contudo, apesar de apresentarem uma linguagem coloquial e recursos linguísticos que facilitam a compreensão do leitor, recomenda-se também que os textos inseridos no LD sejam utilizados através da mediação docente. Uma vez que foi observado que esses textos realizam exclusões de informações, o professor pode acrescentar informações que não estão contidas no texto e debatê-las com os estudantes a fim de conduzir a uma reflexão sobre a temática da água. Pode-se, ainda, relacionar a temática com outras áreas do conhecimento a partir de atividades interdisciplinares (como visitas escolares às Estações de Tratamento de Água e atividades práticas, por exemplo) que estimulem o interesse dos discentes e lhes ofereçam outros recursos para o processo de ensino-aprendizagem.

\section{REFERENCIAS}

Bardin, L. (1977) Análise de conteúdo. $3^{\mathrm{a}}$ ed. Lisboa: Edições 70.

Borges, L. W, Araújo, M. C. P \& Bönmann, L. W. (2016) Recursos hídricos: um tema de aprendizagens significativas em livros didáticos do ensino fundamental. $V$ Congresso Internacional de Tecnologias para o Meio Ambiente, Bento Gonçalves, RS, 1-5. 
Brasil. Secretaria de Educação Fundamental. (1997) Parâmetros Curriculares Nacionais: Ciências Naturais. Brasília: MEC/SEF, 1-90.

Brasil. Secretaria de Educação Fundamental. (1998) Parâmetros Curriculares Nacionais: Ciências Naturais. Brasília : MEC / SEF, 1-139.

Bueno, W. C. (2010) Comunicação Científica e Divulgação Científica: aproximações e rupturas conceituais. Informação \& Informação, Londrina, v. 15, n. esp., 1-12.

Canto, E. L do. (2015). Ciências naturais: aprendendo com o cotidiano. $5^{\mathrm{a}}$ ed. São Paulo: Moderna.

Dias, G.R et al.(2016) Textos de divulgação científica: análise e caracterização para utilização no ensino de matemática. Revista Eletrônica de Educação Matemática, 11(1), 84-98.

Ferrari, P. C, Angotti, J. A \& Cruz, F. F. S. (2005) A divulgação científica na educação escolar: discutindo um exemplo. Atas do VEncontro Nacional De Pesquisa Em Educação Em Ciências, 5, 1-12.

Ferreira, L. N. A \& Queiroz, S. L. (2011) Artigos da revista ciência hoje como recurso didático no ensino de química. Quim. Nova, 34(2), 354-360.

Fioreze, J. Z \& Delizoicov, N. C. (2015) Livros didáticos de Biologia e a história da Ciência. Roteiro, Joaçaba, 40(1), 101-126.

Freitas, N. T. A \& Marin, F. A. D. G. (2016) O tema água e sua inserção nos livros didáticos de ciências do ensino fundamental. Colloquium Humanarum, 13(3), 51-57.

Gil, A. C. (2002) Como elaborar projetos de pesquisa. 4ªed. São Paulo: Atlas.

Goldbach, T \& El-Hani, C. (2008) Entre receitas, programas e códigos: metáforas e ideias sobre genes na divulgação científica e no contexto escolar. Alexandria Revista de Educação em Ciência e Tecnologia, 1(1), 153-189.

Gomes, I. (1995) Dos laboratórios aos jornais: Um estudo sobre o jornalismo científico. (214f.) Dissertação de mestrado do Programa de Pós-graduação em Letras e Linguística. Centro de Artes e Comunicação, UFPE, Recife.

Grillo, S. V. C, Dobranszky, E. A \& Laplane, A. L. F. (2004) Mídia impressa e educação científica: Uma análise das marcas do funcionamento discursivo em três publicações. Cad. Cedes, Campinas, 24(63), 215-236.

Lopes, S. (2015). Investigar e conhecer: ciências da natureza. $1^{\text {a }}$ ed. São Paulo: Saraiva.

Martins, I, Cassab, M. \& Rocha, M. B. (2001) Análise do processo de re-elaboração discursiva de um texto de divulgação científica para um texto didático. Revista Brasileira de Pesquisa em Educação em Ciências, 1(3), 1-9.

Moreira, I. C \& Massarani, L. (2002) Aspectos históricos da divulgação científica no Brasil. In: Massarani, L. Moreira, I \& Brito, F. (2002).Ciência e público: caminhos da divulgação científica no Brasil. Rio de Janeiro: Casa da Ciência, 43- 64.

Nascimento, T. G. (2005) O discurso da divulgação científica no livro didático de ciências: características, adaptações e funções de um texto sobre clonagem. Revista Brasileira de Pesquisa em Educação em Ciências (RBPEC), 5(2), 15-28.

Otalara, A.P \& Carvalho, L. M. (2011) O tema água nos livros didáticos de ciências da natureza, o cotidiano (global-local) e as questões ambientais. Anais do VI Encontro "Pesquisa em Educação Ambiental”, Ribeirão Preto, 1-15. 
Passeri, M.G, Aires, R.M \& Rocha, M. B. (2017) Reelaboração discursiva de um texto de divulgação científica sobre crise hídrica em um livro didático de Ciências. Ensino, Saúde e Ambiente, 10(1), 142-162.

Pereira, A. M, Santana, M \& Waldhelm, M. (2015). Projeto Apoema. $2^{\text {a }}$ Ed. São Paulo: Editora do Brasil.

Santana, A. N.V, Souza, L.N \& Shuvartz, M. (2012) Análise do tema água em livros didáticos de ciências do ensino fundamental. Anais do XVI Encontro Nacional de Didática e Práticas de Ensino, Campinas, Livro 3, 4667- 4677.

Silva, L.L, Pimentel, N.L \& Terrazzan, E. (2011) As analogias na revista de divulgação científica ciência hoje das crianças. Ciência \& Educação, 17(1), 163-181.

Souza, P. H. R. (2017) Análise dos textos de divulgação científica referentes à biologia animal em livros didáticos de biologia para o ensino médio. (223f.) Tese de doutorado. Programa de Pós-Graduação em Ciência, Tecnologia e Educação, Centro Federal de Educação Tecnológica Celso Suckow da Fonseca (CEFET/RJ).

Souza, P. H. R \& Rocha, M. B. (2014) Análise do processo de Reelaboração Discursiva na incorporação de um texto de Divulgação Científica no livro de Ciências. Revista Brasileira de Ensino de Ciência e Tecnologia, 7(1), 53-69.

. (2015a) Sistemática filogenética em revista de divulgação científica: análise da Scientific American Brasil. Alexandria, Florianópolis, 8(1), 75-99.

. (2015b) Caracterização dos textos de divulgação científica inseridos em livros didáticos de biologia. Investigações em Ensino de Ciências, 20(2), 126-137.

. (2017) Análise da linguagem de textos de divulgação científica em livros didáticos: contribuições para o ensino de biologia. Ciência \& Educação, Bauru, 23(2), p. 321-340.

Targino, M. G. (2007) Divulgação científica e discurso. Comunicação \& Inovação, 8(15), 19-28.

Xavier, M. C. F, Freire, A.S \& Moraes, M. O. (2006) A nova (moderna) biologia e a genética nos livros didáticos de biologia no ensino médio. Ciência \& Educação, 12(3), 275-289.

Zamboni, L. M. S. (1997) Heterogeneidade e subjetividade no discurso da divulgação cientifica. (211 f.) Tese de Doutorado, Instituto de Estudos da Linguagem, Universidade Estadual de Campinas. 